Article

\title{
Restraining Na-Montmorillonite Delamination in Water by Adsorption of Sodium Dodecyl Sulfate or Octadecyl Trimethyl Ammonium Chloride on the Edges
}

\author{
Hongliang $\mathrm{Li}^{1,2}{ }^{\text {, }}$ Yunliang Zhao ${ }^{3}$, Tianxing Chen ${ }^{1}$, Yuri Nahmad ${ }^{2}$ and Shaoxian Song ${ }^{1, *}$ \\ 1 School of Resources and Environmental Engineering, Wuhan University of Technology, Luoshi Road 122, \\ Wuhan 430070, China; lihongliang222@126.com (H.L.); chentian2728@163.com (T.C.) \\ 2 Doctorado Institucional de Ingeniería y Ciencia de Materiales, Universidad Autonoma de San Luis Potosi, \\ Av. Sierra Leona 530, San Luis Potosi, C.P. 78210, Mexico; yuri@ifisica.uaslp.mx \\ 3 Hubei Key Laboratory of Mineral Resources Processing and Environment, Wuhan University of Technology, \\ Luoshi Road 122, Wuhan 430070, China; yunliang286@163.com \\ * Correspondence: shaoxian@uaslp.mx
}

Academic Editor: Athanasios Godelitsas

Received: 25 June 2016; Accepted: 18 August 2016; Published: 23 August 2016

\begin{abstract}
The delamination of montmorillonite in water leads to sliming in ore slurry, which is detrimental to mineral flotation and solid/water separation. In this work, the delamination of Na-montmorillonite (Na-MMT) has been restrained by sodium dodecyl sulfate (SDS) or octadecyl trimethyl ammonium chloride (1831) through the adsorption on the edge of the mineral. The experimental results have shown that the pretreatment by adding SDS and 1831 could greatly reduce the Stokes size percentage of $-1.1 \mu \mathrm{m}$ particles in the aqueous Na-MMT suspension. From the X-ray diffractometer (XRD) results, the interlayer spacing of the MMT pre-treated by SDS and 1831 is smaller than that of original MMT particles. Adsorption position of SDS and 1831 on MMT surfaces was analyzed by the measurements of adsorption capacity of SDS and 1831, inductively-coupled plasma spectra, and zeta potential before and after the plane surface of MMT was covered with tetraethylenepentaminecopper $\left([\mathrm{Cu}(\text { tetren })]^{2+}\right)$. The results indicated that SDS and 1831 are adsorbed on the edge and the whole surface of Na-MMT, respectively. Delamination of MMT could be well restrained by the adsorption of SDS and 1831 on the edges of MMT.
\end{abstract}

Keywords: montmorillonite; restraining delamination; mechanical chemical adsorption; surfactants

\section{Introduction}

Na-montmorillonite (Na-MMT) is one kind of 2:1 phyllosilicates with the exchangeable $\mathrm{Na}^{+}$ cation adsorbed in the interlayer space close to the tetrahedral basal oxygen atoms [1]. When the Na-MMT particle is immersed in water, the interlayer of MMT will be hydrated. The interlayer hydration includes (i) hydration of interlayer cations; (ii) interaction of clay mineral surfaces with water molecules and interlayer cations; and (iii) water activity in the clay mineral-water system [2]. Vibrational studies have shown that they are less hydrogen-bonded to each other and the water molecules are strongly polarized by the interlayer cation extending to about $12 \mathrm{H}_{2} \mathrm{O}$ molecules per interlayer cation. These findings are in good agreement with quasi-elastic neutron scattering (QENS) studies which reveal that water diffusion in the interlayer space is about an order of magnitude slower relative to bulk water [3]. Generally, the water molecules forms hydration shells around the interlayer cations which offer the energy for expanding the interlayer space, while the other water molecules get adsorbed into the expanded interlayer space $[4,5]$. After the interlayer is intercalated with water 
molecules and the interlayer space is expanded, the Na-MMT can be easily exfoliated and delaminated into fine nanosheets [6].

The delamination of MMT appears in many separation processes, such as hydrometallurgy, magnetic separation and solid-water separation $[7,8]$. For example, the presence of colloidal MMT in copper leachate would lead to an extreme difficulty for the purification of the leachate [9]. The delamination of MMT would result in the declining of the settling rate of the MMT particles and, thus, poor sedimentation [10]. Furthermore, it would reduce the efficiency of filtering. Thus, it is vital to create a new method to reduce the content of fine particle from tailings slurries which are caused by delamination of Na-MMT in leaching process.

Güven [2] has found that the non-ionic polar organic molecules can replace the adsorbed water on external surfaces of MMT. As a result, the surface of MMT particles can become hydrophobic, losing their tendency to attract water molecules. Sodium dodecyl sulfate (SDS) is an anionic surfactant with the formula $\mathrm{CH}_{3}\left(\mathrm{CH}_{2}\right)_{11} \mathrm{SO}_{4} \mathrm{Na}$. Octadecyl trimethyl ammonium chloride (1831) is a cationic surfactant with the formula $\mathrm{C}_{21} \mathrm{H}_{46} \mathrm{NCl}$. In this work, SDS and 1831 was pre-adsorbed onto the edge surface before immersion of Na-MMT in water, in order to reverse the hydrophilic edge surface to hydrophobic, thereby, preventing water adsorption in the interlayer space and to prevent Na-MMT from delaminating to super fine particles in water. In the processes, surfactant adsorption on MMT would not bring any problem for separation in hydrometallurgy, magnetic separation, and solid-water separation. Therefore, there are significant applications of our finding in this study to the above-mentioned processes. The adsorption position of the surfactant is determined by the adsorption relation between the surfactant and tetraethylenepentaminecopper $\left([\mathrm{Cu}(\text { tetren })]^{2+}\right)$, by which $\left([\mathrm{Cu}(\text { tetren })]^{2+}\right)$ can pre-block the structural charges of MMT.

\section{Experimental}

\subsection{Sample Preparation}

The Na-MMT powder sample was obtained from Chifeng Ningcheng Montmorillonite Co., Inner Mongolia, China. The composition of the sample was characterized using a Bruker D8 Advance X-ray diffractometer (XRD) at a voltage of $40 \mathrm{kV}$ and a current of $30 \mathrm{~mA}$ with $\mathrm{Cu} \mathrm{K}$ radiation $(\lambda=0.15418 \mathrm{~nm})$. Figure 1 gives the XRD pattern, showing that the purity of the sample is very high grade and only contains negligible impurities.

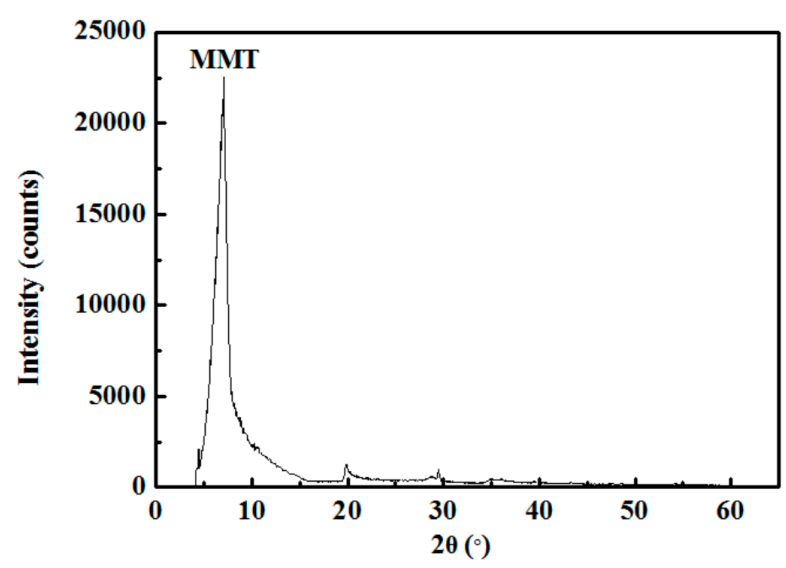

Figure 1. XRD pattern of MMT sample.

The analytical grade $\mathrm{Cu}\left(\mathrm{NO}_{3}\right)_{2} \cdot 3 \mathrm{H}_{2} \mathrm{O}$, tetraethylenepentamine, methyl orange solutions, ethanol, cetylpyridinium bromide, dichloromethane, methylene blue, thymol blue, $\mathrm{Na}_{2} \mathrm{SO}_{4}, 95 \%$ sulfuric acid, SDS and 1831 are obtained from Sigma-Aldrich Co, Shanghai, China. The water was produced using a Millipore Milli-Q Direct 8/16 water purification system (Billerica, MA, USA) with $18.2 \mathrm{M} \Omega$. 


\subsection{Pre-Adsorption of SDS and 1831 on the MMT Surface}

$0.5 \mathrm{~mL}$ liquid agent and $1 \mathrm{~g}$ MMT are added into a grinding tank (diameter $4.5 \mathrm{~cm}$ and height $5 \mathrm{~cm}$ with seven zirconia balls). The mass ratio of ore to agent was 50:1. The MMT and agent were mixed in a QM-3SP04 planetary mill (Shanghai Longtuo Co. Ltd, Shanghai, China) mechanically for $60 \mathrm{~min}$ at $150 \mathrm{rev} / \mathrm{min}$. The MMT paste was dispersed in $80 \mathrm{~mL}$ water by stirring for $3 \mathrm{~min}$ at $450 \mathrm{rev} / \mathrm{min}$. The prepared suspension was used for the measurements of Stokes size. The Stokes size was measured by centrifugal classification using a Thermo Fisher Sorvall ST16 centrifuge (Waltham, MA, USA). The solid in suspension was separated by centrifugation and the solid component was dried in an electro-thermostatic blast oven for $8 \mathrm{~h}$ at $60^{\circ} \mathrm{C}$. The interlayer spacing of the dried powder was detected using a Bruker D8 Advance X-ray diffractometer (XRD) (Karlsruhe, Germany).

\subsection{Detection of Adsorption Position of SDS and 1831 on MMT Surface}

\subsubsection{Adsorption of $[\mathrm{Cu}(\text { tetren })]^{2+}$ on the Plant Surface of MMT}

The delaminated MMT sample named MMT 1 was prepared as follows: $15 \mathrm{~g}$ MMT powder was poured into $500 \mathrm{~mL}$ deionized water and then delaminated for $8 \mathrm{~min}$ using an intermittent sonication at the strength of $60 \%$ by a Vernon Hills Illinois Cp505 ultrasound dispersion (Hielscher, Ringwood, NJ, USA). The ultrasound-treated MMT was separated by centrifuge for $4 \mathrm{~min}$ at 10,000 rev/min and $3 \mathrm{~min}$ at 11,000 rev $/ \mathrm{min}$, in order to get the delaminated supernatant of MMT. Then, the MMT 1 supernatant was obtained by diluted the delaminated supernatant to $0.01 \mathrm{~g} / \mathrm{L}$. Zeta potential of the dilute suspension was measured using a Malvern Zetasizer Zeta-Nano (Malvern, UK).

An analogous procedure was followed to obtain the $[\mathrm{Cu} \text { (tetren) }]^{2+}$ solutions in deionized water. A $0.01 \mathrm{M}[\mathrm{Cu} \text { (tetren) }]^{2+}$ solution was prepared by mixing equal volumes of $0.02 \mathrm{~mol} / \mathrm{L} \mathrm{Cu}\left(\mathrm{NO}_{3}\right)_{2} \cdot 3 \mathrm{H}_{2} \mathrm{O}$ and $0.02 \mathrm{~mol} / \mathrm{L}$ tetraethylenepentamine. $50 \mathrm{~mL}$ of the MMT 1 suspension and $150 \mu \mathrm{L}$ of the $[\mathrm{Cu} \text { (tetren) }]^{2+}$ solution were added to a centrifuge tube. After $24 \mathrm{~h}$ equilibration with shaking, $[\mathrm{Cu} \text { (tetren) }]^{2+}$ was adsorbed onto the plane surface of MMT until saturation to obtain MMT 2 sample. The zeta potential of MMT 2 suspension was measured using a Malvern Zetasizer Zeta-Nano.

\subsubsection{Concentration Measurement of SDS and 1831}

Concentration of SDS can be measured by spectrophotometric quantification method. The colorimetric reaction of the SDS was carried out as follows: $1 \mathrm{~mL}$ desired concentration (from 0-9 mmol/L) of SDS was poured into a $25 \mathrm{~mL}$ volumetric flask. $24 \mathrm{~mL}$ coloring solution was poured into the volumetric flask and allowed to react for $2 \mathrm{~h}$. The SDS solution was colored and the absorbance of the solutions was measured using a Thermo Genesys spectrophotometer (Waltham, MA, USA). The coloring solution was obtained as follows: $20 \mathrm{~mL}$ methyl orange solutions, $100 \mathrm{~mL}$ ethanol, $20 \mathrm{~mL}$ cetylpyridinium bromide solutions, $100 \mathrm{~mL}$ ethanol, and $760 \mathrm{~mL}$ deionized water were poured into a $1000 \mathrm{~mL}$ volumetric flask in order. Both the concentrations of the methyl orange solutions and the cetylpyridinium bromide solutions are $2.5 \mathrm{mmol} / \mathrm{L}$. The mixed solution was reacted for $3 \mathrm{~h}$ in the volumetric flask.

The concentration of 1831 in aqueous solutions was determined by titration. Octadecyl trimethyl ammonium chloride (1831) is one kind of cationic surfactant with the formula $\mathrm{C}_{21} \mathrm{H}_{46} \mathrm{NCl}$. The titration solution was 1831. The titrate solutions was prepared as follows: $20 \mathrm{~mL}$ SDS solutions, $5 \mathrm{~mL}$ mixed indicator, $5 \mathrm{~mL}$ acidity $\mathrm{Na}_{2} \mathrm{SO}_{4}$ solutions, $10 \mathrm{~mL}$ deionized water, and $15 \mathrm{~mL}$ dichloromethane was poured into a beaker in order. The concentration of SDS was $3 \mathrm{mmol} / \mathrm{L}$. The 1831 solution was dropped into the titrate solutions until the pink phase turned colorless. The amount of the 1831 was equals to the dropped SDS. The standard curve of 1831 is shown in Figure $2 b$.

The mixed indicator was obtained by mixing $225 \mathrm{~mL}$ thymol blue solutions with $30 \mathrm{~mL}$ methylene blue solutions. The thymol blue solutions was prepared as follows: $0.05 \mathrm{~g}$ thymol blue was dissolved in $50 \mathrm{~mL} 20 \%$ ethanol water solutions. The supernatant was separated by filtration and then diluted to $500 \mathrm{~mL}$. The concentration of methylene blue solutions was $0.036 \mathrm{~g} / \mathrm{L}$. The acidity $\mathrm{Na}_{2} \mathrm{SO}_{4}$ solutions 
was obtained as follows: $100 \mathrm{~g} \mathrm{Na}_{2} \mathrm{SO}_{4}$ was poured in $12.6 \mathrm{~mL} 95 \%$ sulfuric acid solutions and then dissolved and diluted to $1 \mathrm{~L}$.

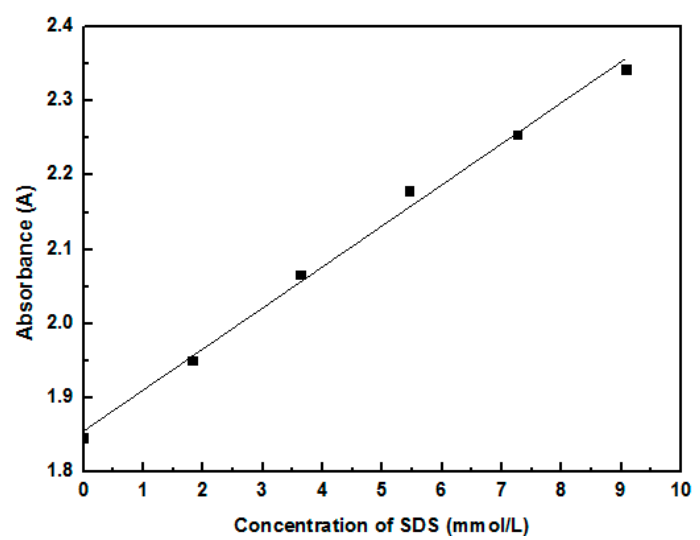

(a)

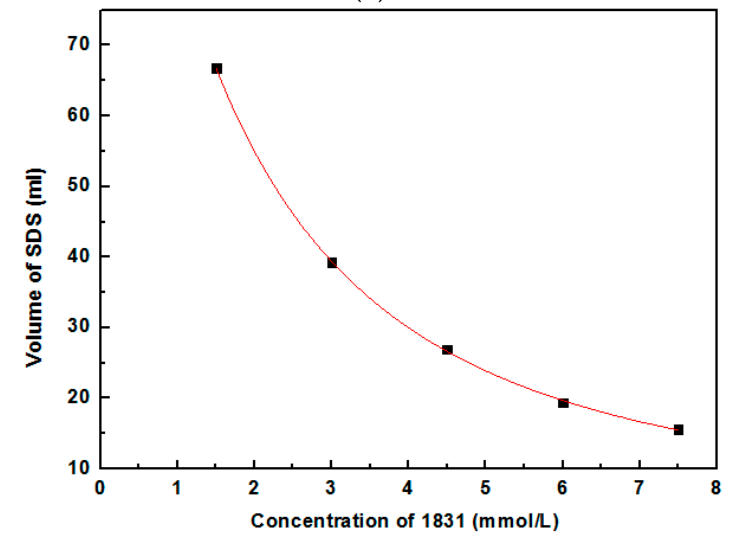

(b)

Figure 2. Standard curve of SDS and 1831. (a) SDS; and (b) 1831.

\subsubsection{Adsorption Position of SDS and 1831 on the MMT Surface}

Adsorption position of SDS and 1831 was determined by the adsorption isotherms results, zeta potential result, and exchange of $\mathrm{Cu}$ content on the surface of MMT 1/MMT 2. Firstly, $0.5 \mathrm{~mL}$ SDS/1831 with certain concentration was added into $5 \mathrm{~mL}$ MMT 1/MMT 2 suspensions. After that, suspensions were diluted to $50 \mathrm{~mL}$ with deionized water and reacted for $12 \mathrm{~h}$. The concentration of SDS and 1831 in liquid phase was determined by spectrophotometric quantification and titration methods, respectively. The zeta potential of the prepared suspension was measured by using a Malvern Zetasizer Zeta-Nano (Malvern, UK). To measure the Cu content of the samples and the concentration of surfactants, suspension was centrifuged for $2 \mathrm{~min}$ at $4000 \mathrm{rev} / \mathrm{min}$ in order to separate the solid and liquid. After that, the solid sample was dried in an electro-thermostatic blast oven for $8 \mathrm{~h}$ at $60^{\circ} \mathrm{C}$ in order to detect the $\mathrm{Cu}$ content. Then, $\mathrm{Cu}$ content of the prepared sample was detected by a Perkin Elmer Optima 4300DV inductively-coupled plasma spectrometer (ICP) (Waltham, MA, USA).

\section{Results and Discussion}

\subsection{Restraining Montmorillonite Delamination}

The Stokes size of the MMT in water after adsorbed SDS and 1831 are presented in Figure 3. The Stokes size percentage of $-1.1 \mu \mathrm{m}$ particles of MMT pre-treated by SDS and 1831 was $10.1 \%$ and $9.2 \%$, respectively. These two values are much larger than those of original MMT (32.2\%), indicating that the Stokes size of the original MMT was finer than that which was pre-treated by SDS and 1831. 
It means that the delamination was restrained by pre-adsorption of SDS and 1831. The delamination of Na-MMT in water is often caused by the interlayer hydration [6,11-20]. However, after $1 \mathrm{~h}$ mixing in planetary mill, the agent and MMT particles mixed with each other sufficiently. The SDS and 1831 were adsorbed onto the MMT surface and the surface was changed to hydrophobic before the MMT was immersed in water. Then, the water molecule was block out of the interlayer and the interlayer hydration was restrained. In this case, the effect of delamination was weakened by pre-adsorption of SDS and 1831.

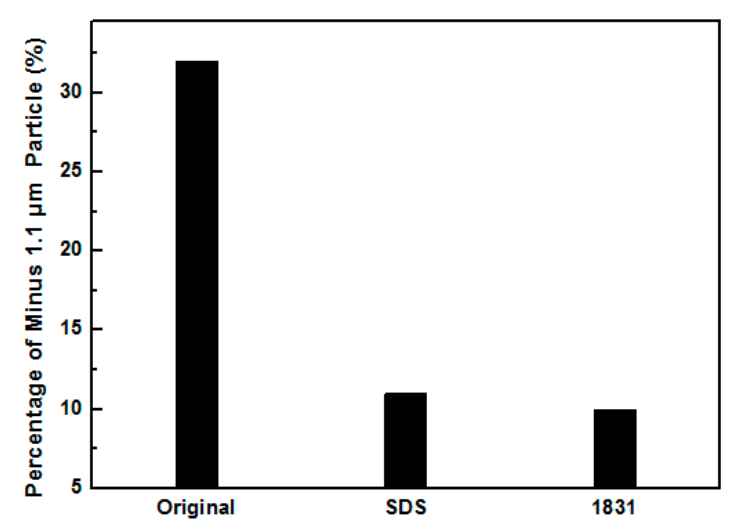

Figure 3. Stokes percentage of minus $1.1 \mu \mathrm{m}$ particle in aqueous solutions pre-treated by of SDS and 1831.

Figure 4 shows the XRD pattern of MMT pre-treated by SDS and 1831. The interlayer spacing of the original MMT and MMT treated by the agent was measured by XRD. The results show that the interlayer spacing of the original MMT is mainly including two different kinds: 1.24 and $1.34 \mathrm{~nm}$. It can be known that the MMT with the interlayer spacing of $1.34 \mathrm{~nm}$ was interlayer hydrated and can be delaminated in water. After MMT particles was dried in an electro-thermostatic blast oven at $60{ }^{\circ} \mathrm{C}$, some of the hydrated water molecules of $\mathrm{Na}^{+}$still remained around [21] and the interlayer spacing was turned to $1.34 \mathrm{~nm}$. It can be inferred that the interlayer counter ions offers the hydration energy for these MMT particles adsorbing water molecules and expanding the interlayer spacing in water. Then, leading to these MMT particles delaminated to fine particles [6,19-21]. Figure 4 also shows that the interlayer spacing of MMTs adsorbed with SDS and 1831 are both $1.24 \mathrm{~nm}$, which was less than that of original MMT (1.34 nm). The smaller interlayer spacing can be attributed to the hydrophobization of MMT which can prevent the intercalation of water into the interlayer space. In this case, XRD results confirmed that the interlayer hydration of MMT was restrained by the adsorption of SDS and 1831.

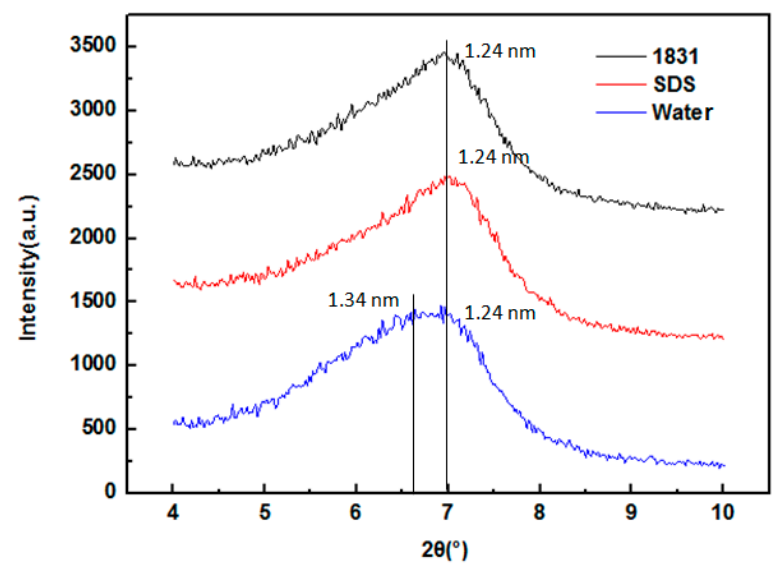

Figure 4. XRD pattern of MMT particles pre-treated by mechanical chemical adsorption of SDS and 1831. 


\subsection{Adsorption Position of SDS and 1831 on the Surface of MMT}

Adsorption position of SDS and 1831 was measured by the adsorption capacity on the different surface of MMT. Firstly, the plane surface of MMT 1 was covered with $[\mathrm{Cu}(\text { tetren })]^{2+}$ to prepare MMT 2. The zeta potential of MMT 1 and MMT 2 are shown in Figure 5. The zeta potential of MMT 2 was around $0 \mathrm{mV}$, meaning that the plant surface was fully covered with $\left[\mathrm{Cu}(\text { tetren) }]^{2+}\right.$. After that, the adsorption capacity of SDS and 1831 on the surface of MMT 1 and MMT 2 was measured. The adsorption capacity is shown in Figures 6 and 7, respectively, and, the content of Cu adsorbed on MMT 2 surface after being treated by SDS and 1831 are shown in Figure 8. The results show that the adsorption capacity of SDS and 1831 was similar before and after the MMT adsorbed $[\mathrm{Cu}(\text { tetren})]^{2+}$. However, the content of $\mathrm{Cu}$ on MMT 2 treated by SDS was much higher than that of treated by 1831 . These results indicated that the $[\mathrm{Cu} \text { (tetren) }]^{2+}$ adsorbed on the plant surface can be replaced by 1831 , but cannot be replaced by SDS. Because the SDS adsorption capacity was similar before and after the MMT was adsorbed with $[\mathrm{Cu} \text { (tetren) }]^{2+}$, it can be known that SDS cannot be adsorbed on the plant surface of MMT. Thus, the adsorption capacity of SDS on the MMT surface can be attributed to the adsorption on edge surface. Since the $[\mathrm{Cu}(\text { tetren })]^{2+}$ adsorbed on the plant surface can be replaced by 1831 , it means that 1831 was adsorbed on the whole surface of MMT. Since the MMT cannot be delaminated in water after being treated with SDS, then, the delamination of MMT can be restrained as long as the surfactant was adsorbed on the edge surface of MMT.

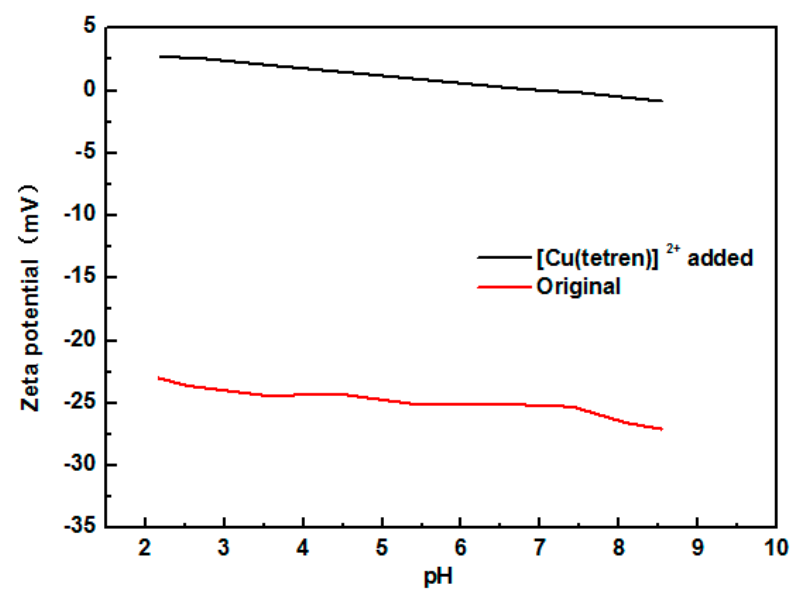

Figure 5. Zeta potential of MMT treated with $[\mathrm{Cu}(\text { tetren })]^{2+}$.

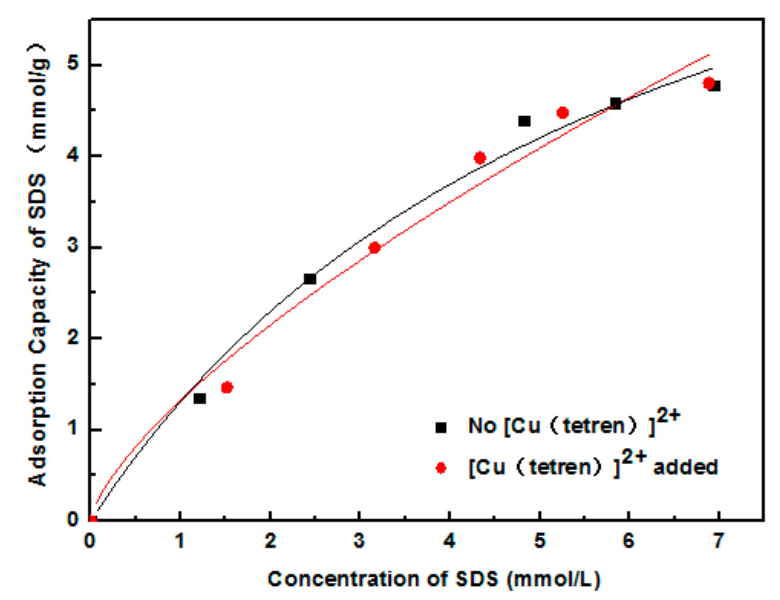

Figure 6. Adsorption capacity of SDS on the surface of original MMT sample and the MMT sample adsorbed with $[\mathrm{Cu}(\text { tetren })]^{2+}$. 


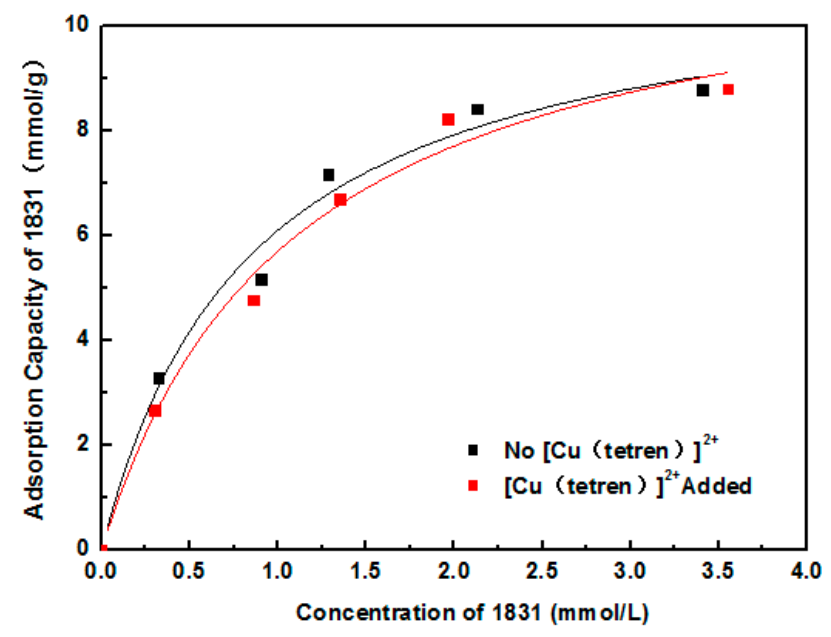

Figure 7. Adsorption capacity of 1831 on the surface of the original MMT sample and the MMT sample adsorbed with $[\mathrm{Cu}(\text { tetren })]^{2+}$.

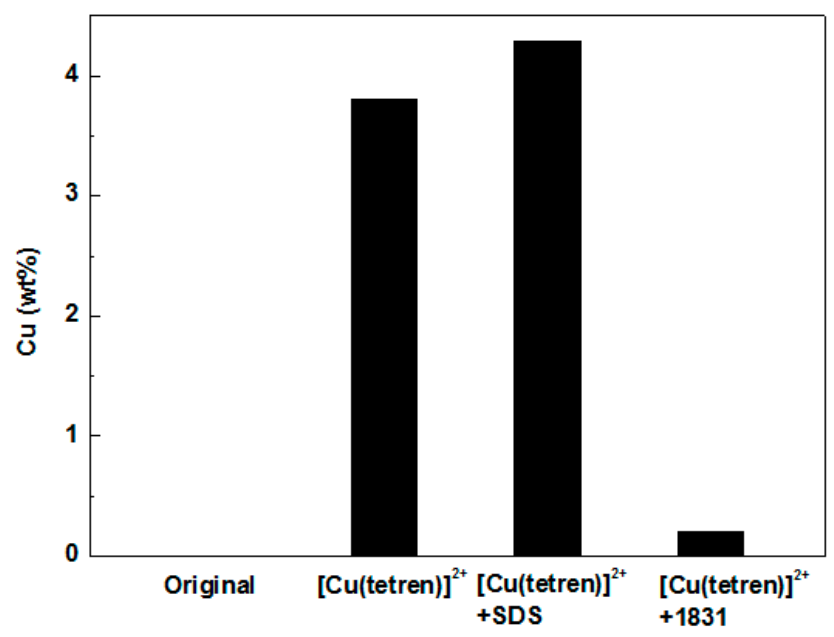

Figure 8. Content of $\mathrm{Cu}$ in MMT samples treated by different methods.

Figure 9 shows the zeta potential of MMT 2 in different concentration of SDS solutions. The zeta potential of MMT 2 decreased as the concentration of SDS increased. This result reconfirmed that the SDS was adsorbed onto the edge surface of MMT. SDS was one kind of anion surfactant, meanwhile, the plane surface of the MMT has a permanent negative charge [22], it can be inferred that the SDS cannot adsorbed onto the plane surface of MMT. Then, the decreasing of zeta potential of MMT 2 would attribute to the adsorption of SDS on the edge surface of MMT.

Figure 10 shows the zeta potential of MMT 2 in different concentrations of 1831 solutions. The results show that the zeta potential of MMT 2 will decrease with the increase of 1831 concentration when the 1831 concentration lower than $0.30 \mathrm{mmol} / \mathrm{L}$. When the concentration of 1831 is higher than $0.30 \mathrm{mmol} / \mathrm{L}$, the zeta potential will increase with the increase of 1831 concentration. This result reconfirmed that the 1831 can adsorbed onto the whole surface of MMT. At the beginning, the $[\mathrm{Cu}(\text { tetren })]^{2+}$ was adsorbed on the plane surface of MMT 2. As one kind of cationic surfactant, the 1831 will adsorb onto the plane surface of MMT and the $[\mathrm{Cu}(\text { tetren })]^{2+}$ will be replaced when the concentration of 1831 is lower than $0.30 \mathrm{mmol} / \mathrm{L}$. The valence of 1831 is +1 , which is smaller than that of $[\mathrm{Cu} \text { (tetren) }]^{2+}$, leading to the decrease of positive charge on the plane surface of MMT. After the concentration of 1831 is raised higher than $0.30 \mathrm{mmol} / \mathrm{L}$, the zeta potential of the 1831 increased as more of the 1831 molecule was adsorbed onto the whole surface of the MMT 2. Thus, the 1831 was adsorbed on the whole surface of MMT. 


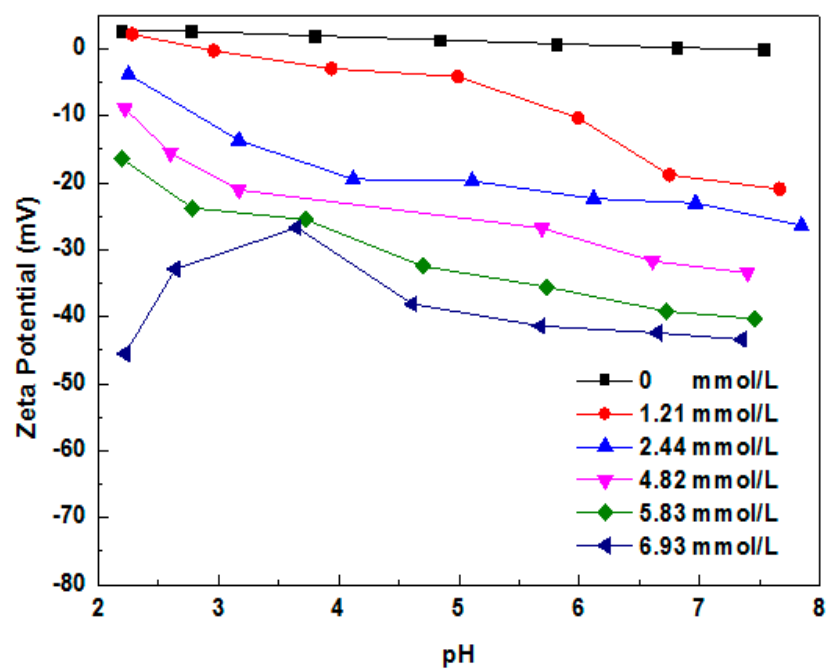

Figure 9. Zeta potential of MMT samples immersed in different concentration of SDS solutions with various $\mathrm{pH}$ values.

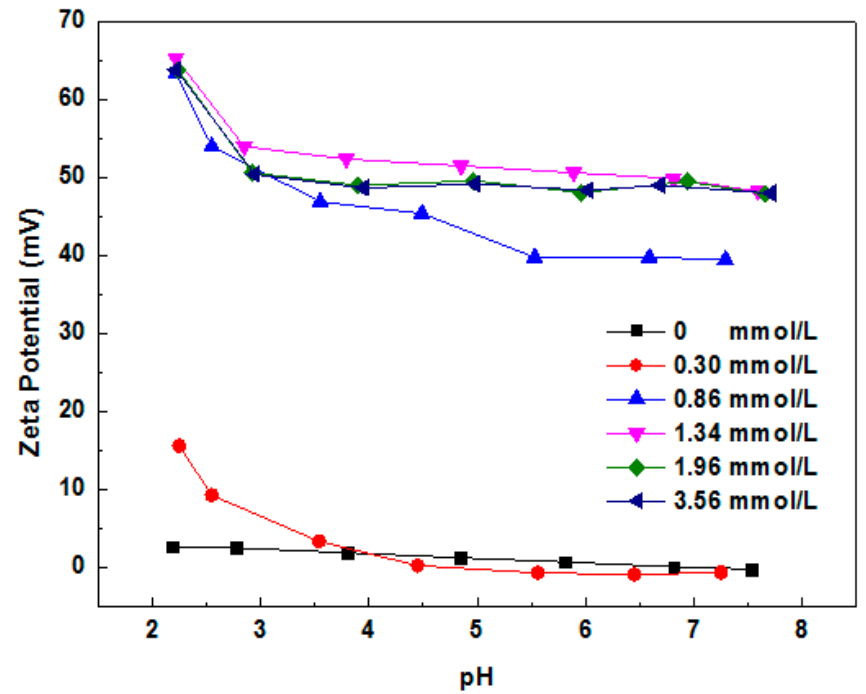

Figure 10. Zeta potential of MMT samples immersed in different concentrations of 1831 solutions with various $\mathrm{pH}$ values.

In summary, the adsorption position of SDS and 1831 on the surface of MMT are show in Figure 11. Figure 11 shows the original MMT particles, the adsorption position of $[\mathrm{Cu}(\text { tetren })]^{2+}$, the co-relationship of adsorption of SDS and $[\mathrm{Cu}(\text { tetren })]^{2+}$, the adsorption position of 1831 on the surface of MMT, the adsorption position of SDS, respectively. The experiential results in Figure 11d,c indicate that the $[\mathrm{Cu} \text { (tetren) }]^{2+}$ adsorbed on the plant surface can be replaced by 1831 but cannot be replaced by SDS, and the $[\mathrm{Cu} \text { (tetren) }]^{2+}$ can be adsorbed onto the edge surface of MMT caused by the adsorption of SDS on the edge surface, as shown by Figure 11c. Therefore, SDS was only adsorbed on the edge surface of MMT and 1831 was adsorbed both on the edge surface and plant surface of MMT, meanwhile, as shown in Figure 11e,d, respectively. 


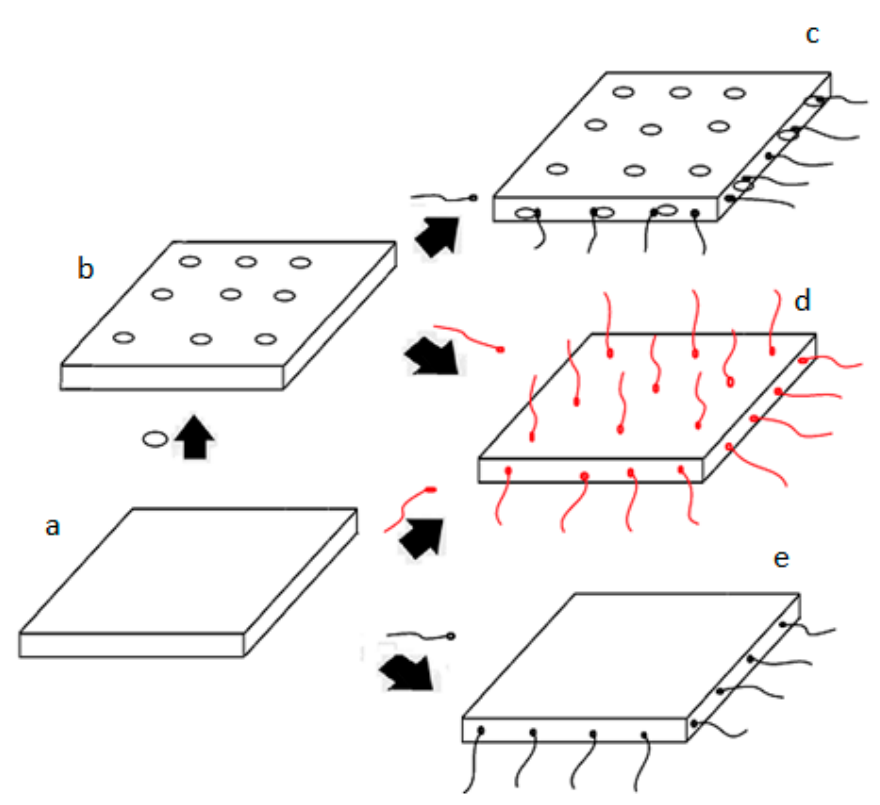

Figure 11. Schematic representation of the adsorption position of SDS and 1831 on the surface of MMT

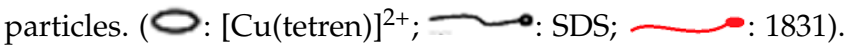

\section{Conclusions}

(1) The SDS and 1831 can be pre-adsorbed onto the edge surface of MMT mixed by grinding. The edge surface of MMT was turned hydrophobic before the MMT was immersed into water. The water molecule was block out of the interlayer space and the interlayer hydration was avoided when the MMT was immersed in water. Delamination of montmorillonite in water can be restrained by pre-adsorption of SDS and 1831.

(2) SDS is only adsorbed on the edge surface of MMT, while 1831 is adsorbed on both of the edge and plane of MMT. The hydrophobization of edge surface of MMT is useful in restraining delamination of MMT.

Acknowledgments: The financial supports to this work from the National Natural Science Foundation of China under the project No. 51474167 was gratefully acknowledged. Also, Hongliang Li would like to thank the Consejo Nacional de Ciencia y Tecnologia of Mexico for offering him the scholarship under the grant No. 595986 during his Ph.D. studying.

Author Contributions: Hongliang Li and Shaoxian Song conceived and designed the experiments; Hongliang Li and Yunliang Zhao performed the experiments; Hongliang Li, Shaoxian Song and Yuri Nahmad analyzed the data; Tianxing Chen and Yunliang Zhao contributed reagents/materials/analysis tools; Hongliang Li and Shaoxian Song wrote the paper.

Conflicts of Interest: The authors declare no conflict of interest.

\section{References}

1. Skipper, N.T.; Sposito, L.G.; Chou Chang, F.R. Monte Carlo simulation of interlayer molecular structure in swelling clay minerals. 2. Monolayer hydrates. Clays Clay Miner. 1995, 43, 294-303. [CrossRef]

2. Güven, N. Molecular aspects of clay-water interactions. In Clay-Water Interface and Its Rheological Implications; Güven, N., Pollastro, R.M., Eds.; CMS Workshop Lectures; The Clay Minerals Society: Chantilly, VA, USA, 1992; Volume 4, pp. 1-80.

3. Malikova, N.; Cadene, A.; Dubois, E.; Marry, V.; Durand-Vidal, S.; Turq, P.; Breu, J.; Longeville, S.; Zanotti, J.M. Water diffusion in a synthetic hectorite clay studied by quasi-elastic neutron scattering. J. Phys. Chem. C 2007, 111, 17603-17611. [CrossRef]

4. Johnston, C.T.; Sposito, G.; Erickson, C. Vibrational probe studies of water interactions with montmorillonite. Clays Clay Miner. 1992, 40, 722-730. [CrossRef] 
5. Swenson, J.; Bergman, R.; Longeville, S. A neutron spin-echo study of confined water. J. Chem. Phys. 2001, 115, 11299-11305. [CrossRef]

6. Sposito, G.; Grasso, D. Electrical double layer structure, forces, and fields at the clay water interface. In Interfacial Forces and Fields: Theory and Applications; Hsu, J.P., Ed.; Marcel Dekker: New York, NY, USA, 1999; pp. 207-249.

7. Bussière, B. Hydrogeotechnical properties of hard rock tailings from metal mines and emerging geoenvironmental disposal approaches. Can. Geotech. J. 2007, 44, 7-40. [CrossRef]

8. Biggs, S. Aggregate structures and solid-liquid separation processes. KONA Powder Part. J. 2006, 24, 41-53. [CrossRef]

9. Jergensen, G.V. Copper Leaching, Solvent Extraction, and Electrowinning Technology; SME: Littleton, CO, USA, 1999.

10. Gorakhki, M.H.; Bareither, C.A. Salinity effects on sedimentation behavior of kaolin, bentonite, and soda ash mine tailings. Appl. Clay Sci. 2015, 114, 593-602. [CrossRef]

11. Norrish, K. The swelling of montmorillonite. Discuss. Faraday Soc. 1954, 18, 120-134. [CrossRef]

12. Norrish, K.; Rausell-Colom, J.A. Low-angle X-ray diffraction studies of the swelling of montmorillonite and vermiculite. In Proceedings of the 10th National Conference on Clays and Clay Minerals, Austin, TX, USA, 14-18 October 1961; Shineford, A., Franks, P.C., Eds.; Pergamon Press: New York, NY, USA, 1963; pp. 123-149.

13. Cebula, J.D.; Thomas, R.K.; White, J.W. Small angle neutron scattering from dilute aqueous dispersions of clay. J. Chem. Soc. Faraday Trans. 1 Phys. Chem. Condens. Phases 1980, 76, 314-321. [CrossRef]

14. Schramm, L.L.; Kwak, J.C.T. Influence of exchangeable cation composition on the size and shape of montmorillonite particles in dilute suspension. Clays Clay Miner. 1982, 30, 40-48. [CrossRef]

15. Nadeau, P. The physical dimensions of fundamental particles. Clay Miner. 1985, 20, 499-514. [CrossRef]

16. Avery, R.G.; Ramsay, J.D.F. Colloidal properties of synthetic hectorite clay dispersions. III. Light and small angle neutron scattering. J. Colloid Interface Sci. 1986, 109, 448-454. [CrossRef]

17. Sposito, G. The diffuse-ion swarm near smectitic particles suspended in 1:1 electrolyte solutions: Modified Gouy-Chapman theory and quasicrystal formation. In Clay-Water Interface and Its Rheological Implications; Güven, N., Pollastro, R.M., Eds.; CMS Workshop Lectures; The Clay Minerals Society: Chantilly, VA, USA, 1992; Volume 4, pp. 128-155.

18. Jasmund, K.; Lagaly, G. Tonminerale und Tone. Struktur, Eigenschaften, Anwen-Dung und Einsatz in Industrie und Umwelt; Steinkopff: Darmstadt, Germany, 1993; pp. 10-20. (In German)

19. Lagaly, G. From clay mineral crystals to colloidal clay mineral dispersions. In Coagulation and Flocculation. Theory and Applications; Dobias, B., Ed.; Marcel Dekker: New York, NY, USA, 1993; pp. 427-494.

20. Lagaly, G. From clay minerals to clay mineral dispersions. In Coagulation and Flocculation, 2nd ed.; Stechemesser, H., Dobias, B., Eds.; Taylor and Francis: Boca Raton, FL, USA, 2005; pp. 519-600.

21. Morodome, S.; Kawamura, K. In situ X-ray diffraction study of the swelling of montmorillonite as affected by exchangeable cations and temperature. Clays Clay Miner. 2011, 59, 165-175. [CrossRef]

22. Brigatti, M.F.; Galan, E.; Theng, B.K.G. Chapter 2: Structure and minerlaogy of clay minerals. In Hand Book of Clay Science; Elsevier: Amsterdam, The Netherlands, 2012; p. 42.

(C) 2016 by the authors; licensee MDPI, Basel, Switzerland. This article is an open access article distributed under the terms and conditions of the Creative Commons Attribution (CC-BY) license (http://creativecommons.org/licenses/by/4.0/). 